\title{
The Giant Footprints
}

\author{
A Lived Sense of Story and Place
}

\author{
Holly Cusack-McVeigh
}

\begin{abstract}
Holly Cusack-McVeigh is a research anthropologist and adjunct professor of anthropology at the University of Alaska's Kenai Peninsula College. Her most recent research explores oral history and folklore on the Bering Sea Coast. In this essay, she retraces her experiences hearing "The Giant Footprints," a Yup'ik Eskimo story from the village of Hooper Bay. The story relates how two young girls disappeared into the land when they failed to follow proper menstrual practices. The place where this occurred is a constant, tangible reminder of how to act, and the story of the girls is retold to reinforce these cultural lessons. The author carefully recorded the settings in which she was told the story and how people were using the story to teach her about Yup'ik culture and beliefs.
\end{abstract}

On the shore of the Bering Sea, between the mouths of the Yukon and Kuskokwim rivers, lies the Yup'ik Eskimo village of Hooper Bay. In the early 1840s L. A. Zagoskin, a Russian naval lieutenant, wrote that the people of this region were known as Magmyut, "those who lived on the level tundra places" (Michael 1967:210). E. W. Nelson, an American naturalist for the Smithsonian Institution, also wrote about this place as he traveled throughout the region collecting natural history specimens and material culture. At the time of 


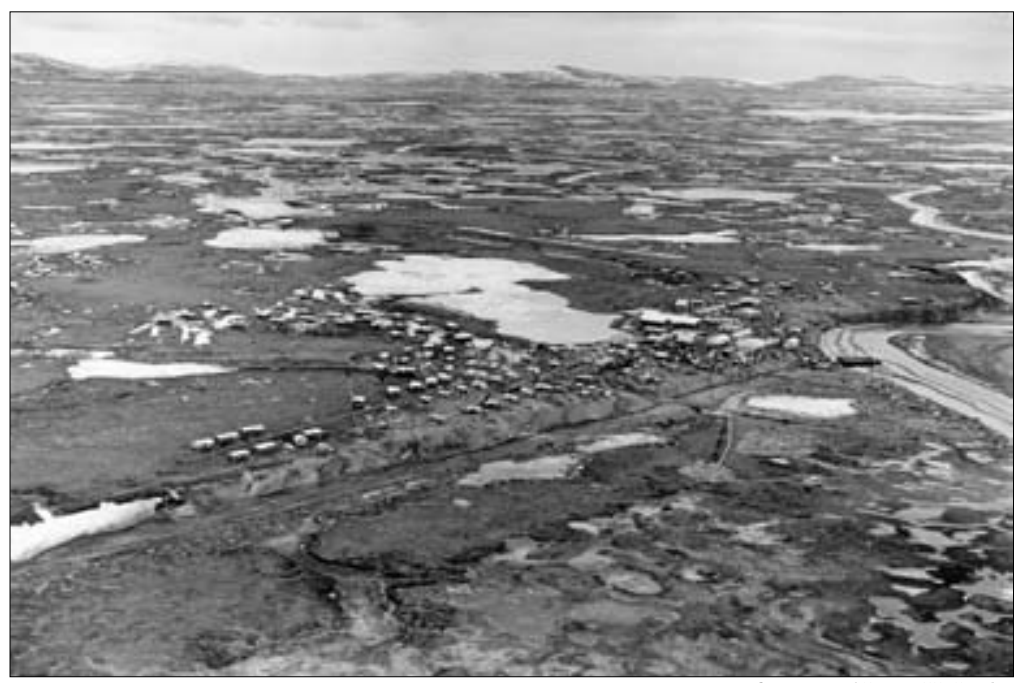

Courtesy of James H. Barker

Yup'ik Village on the Yukon-Kuskokwim Delta.

Nelson's 1878 visit, Hooper Bay was known as Askinuk. Few outsiders had come to this part of the Yukon-Kuskokwim Delta before Nelson's arrival. The 1890 census report states that "the inhabitants are Magmiuts, 138 in number, who live in 14 dwellings and 2 kashgas [ceremonial houses]" (Report on the Population and Resources of Alaska at the 11th Census, 1890:111).

Much has changed in Hooper Bay since Nelson's visit. The present-day village is one of the largest villages in Alaska, with well over a thousand community members. In spite of a tumultuous history and the impact of dramatic change (Napoleon 1991), the oral traditions continue to be a central aspect of contemporary life. Among Yupiit, places and their stories serve as a reference, barometer, and guide.

During my first week in Hooper Bay, now more than ten years ago, a group of young men invited me to go set nets in the mouth of the river across the bay. I had come to their village to contextualize an archival photographic collection. Consequently, I had spent many hours working and visiting with their grandmother, a respected community elder. I jumped at the chance to get out and explore. Their family loaned me a pair of waders and we set off for the row of skiffs lined up along the shoreline. It was a wonderful day and we all enjoyed being "out on the land." We set several nets, walked the beaches where we discovered the carcass of a large whale, and took turns at target practice with a .22 rifle. On our 


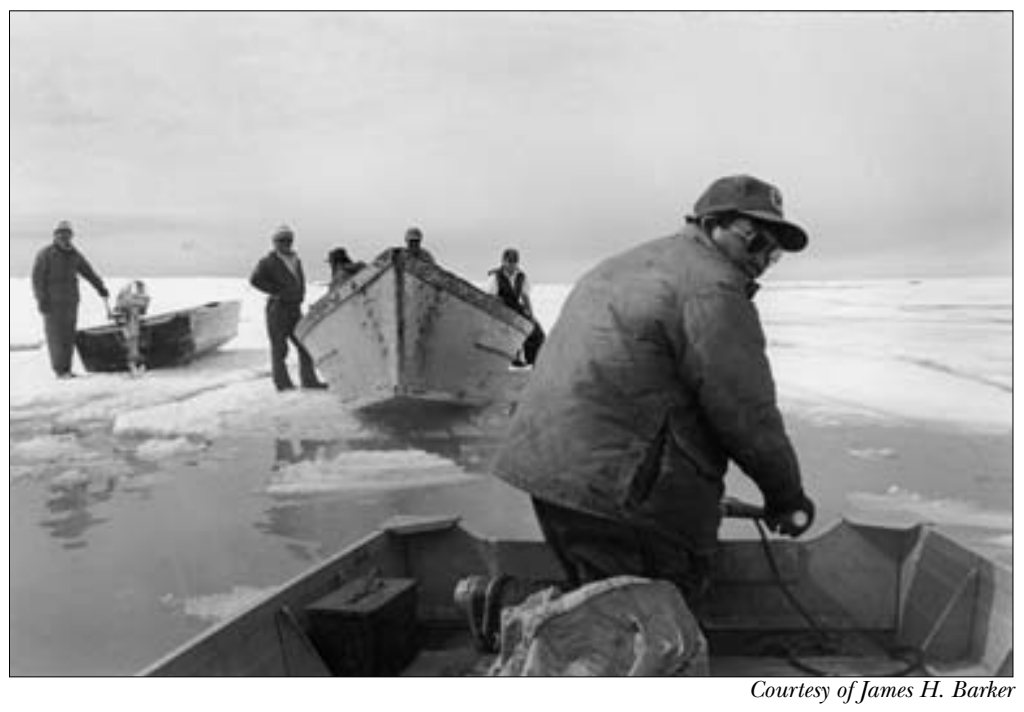

Men departing for a seal hunt.

return trip a seal presented itself in the bay. ${ }^{1}$ After a lengthy pursuit we finally gave up when it lead us out into the rough, choppier waters of the open sea. I recall my deep disappointment as this, my first "seal hunt," had ended in failure. I silently questioned the experience and skill of these young hunters. After all, we had lost the seal, prized for both its delicious meat and seal oil. ${ }^{2}$

When we reached the village shore we began gathering up our nets and other supplies. As we worked to unload the skiff one of them asked, "Have you seen the giant footprints?" When I replied that I had not, they quickly offered to take me to this place on the tundra. We jumped onto their four-wheelers and headed out onto the tundra, making our way up the coast. As we approached I could easily see them at a distance: large, deep depressions extending out before us. I was anxious to get down and examine them closer, but I was teasingly warned by these young men not to step directly into these footprints. I cautiously and respectfully walked around them, although I didn't fully understand why.

One of the first stories I ever heard in Hooper Bay is tied to this particular place on the tundra. The story of "The Giant Footprints" recalls how the people were holding a feast and dancing down at the old village site of Askinuk. As was the custom, two young girls who had just begun menstruation were left behind. The sound of singing and drumming enticed the young girls to sneak out and head 
towards the celebration. Tellers often explicitly state that the girls disregarded what they knew to be appropriate behavior. ${ }^{3}$ Tellers go on to describe the excitement of the young girls as they headed towards the ceremony, but as they crossed the tundra the ground began to "roll" and move. At this point, one teller explained to me that the "earth used to be much thinner" than it is today. As the girls tried to make their way towards the celebration, they started to sink. The more they struggled, the more they sank down. They sank into the tundra and became lost to the world of the living. They became a part of another world, a world that is not entirely separate from the world of the living, but they were never seen again.

Every version that I have been told of "The Giant Footprints"4 is similar in content. This narrative emphasizes that these young girls had just begun puberty. The tellers often stop to explicitly explain to me that, in traditional Yup'ik Eskimo belief, girls should not go out in public or dance during their time of menstruation. ${ }^{5}$ It was customary for girls to remain indoors and away from the rest of the family and community members during this time. Nelson himself wrote that "a particular atmosphere is supposed to surround her at this time, and if a young man should come near enough for it to touch him it would render him visible to every animal he might hunt, so that his own success as a hunter would be gone" (Nelson 1983 [1899]: 291).

A Jesuit missionary at Hooper Bay during the 1930s wrote that "while menstruation is going on she is not allowed to leave the house but has to hide herself in one corner of the igloo [sod house]. And if the family just happens to have to move camp while she is in this condition she has to be laid in the sled and covered up so that she can not see anything, nor touch the ground. If she would touch the ground hunters would have bad luck, and spirits would likely take her soul away" (AM Collection 30:1105-1213).

In May of 2000 I worked with community members on a project entitled "Sharing Our Traditions: Searching for Meaning." The tribal council met to discuss this project and the following month, in June of 2000, I returned again to help carry out the objectives outlined in the proposal. This time I traveled to Hooper Bay with my six-year-old son. One day my son and I were walking to the store when one of the council members, another community elder, stopped us. My son eagerly ran off to play with a group of children while we visited and talked about the project. As we watched the kids playing nearby, this man spoke of other Hooper Bay elders 
he thought should be included in the project. With what seemed to be an abrupt shift in our conversation, he began to talk about the giant footprints. As he spoke, he pointed to the open tundra behind me where the deep depressions mark the land. He told me the story of the young girls and explained to me that those giant footprints were out there on the land today.

Like previous tellings I had heard, he explained that the footprints were made by two young girls who had ignored the wisdom of their elders. They had not respected the Yup'ik behavioral rules regarding menstruation. I was, admittedly, intrigued by one aspect of his story in which the girls "are now up in the sky." I immediately recalled Nelson's writings in which he had described a "sky land" in reference to Yup'ik stories of Raven (Nelson 1983 [1899]). I wondered how this fit with the girls being taken into the land. I must have let my curiosity show because he seemed to know that this tale had piqued my interest. Smiling at me he stated "you will hear about that one." Nodding his head with assurance he told me again, "You will hear more about them [the giant footprints]!" We then parted company. I found my son and we were once again off to the store.

As we made our way up the hill toward the old part of the village, I wished that I had taken this opportunity to ask him more about this narrative. I thought, "I missed my chance again!" Then, laughing to myself, I recalled the lesson I had learned so many times before. As folklorists Phyllis Morrow and William Schneider remind their readers, "words return." Stories and narratives, like the seals who have been hunted and killed, return to those who demonstrate respect and patience (Morrow and Schneider 1995). Words return as stories to find you!

While conducting archival research, I discovered that this narrative had also been shared with Helen Oswalt (then a University of Alaska Fairbanks graduate student) when she visited Hooper Bay back in 1950. Her field notes state that:

Once there was very thin land here. Two girls were left in [a] hut their family built for their puberty (they wore hoods) while rest of village went to sealing camp. Girls heard dance music, [and] knew they weren't allowed to go but wanted to. All who go to dances must take something [an offering] so they took the leftak [sic] skin from the doorway and started out with it between them. After walking a while, they began sinking in the shallow ground and then began going up to 
the sky. They started back another way, and the same thing happened. They disappeared in [the] sky, but footsteps can still be seen here. (Oswalt 1951:11)

This 1950 telling is strikingly similar in detail to the versions that have been shared with me over the years by various tellers at Hooper Bay, except that here sinking into the ground and ascending into the sky were again linked in the same telling. The elder who shared this story with me when we met on the road had said, "you will hear more about them," and he was right. Later that same year, I would find myself sitting with another well-respected elder as we recorded his life history, and he too would weave this narrative of the "Giant Footprints" into his own story. He smiled with pride as he recalled the place where he got his first seal as a young boy and he described the many places on the tundra where he had learned to hunt birds with his grandfather. He recalled, too, the many times he had passed those giant footprints. He then shared this story of the young girls before turning back to his own personal narrative. This is an important feature of storytelling in Hooper Bay. People connect their own life story to places on the land and in doing so connect the stories of place to their own experiences. It is an integral part of Yup'ik belief and sense of place. Hastrup, in recording life histories in an Icelandic community, has similarly noted this aspect of oral tradition in relation to place. She writes that "we were not only met with a life history, but also a life space" (Hastrup 1998:112).

In October of 2001, a Hooper Bay community member and I decided to give a paper at the annual meeting of the American Folklore Society held in Anchorage, Alaska. The theme of the conference was "partners in knowledge." We were invited to participate in a session that explored "The Power of Alaskan Places." We had recently conducted a recorded interview with another community elder who had shared with us the story of "The Giant Footprints." We decided to ask this particular elder to join us in our presentation. What proved to be most valuable was the time that the three of us spent together preparing for our public presentation.

As we sat in an empty conference room at the Hilton Hotel, we listened to this elder tell the story of "The Giant Footprints" as she planned to tell it to our larger, intended audience. What was most fascinating was the way that she embedded, in this widely known tale, her personal narrative. As she described the young 


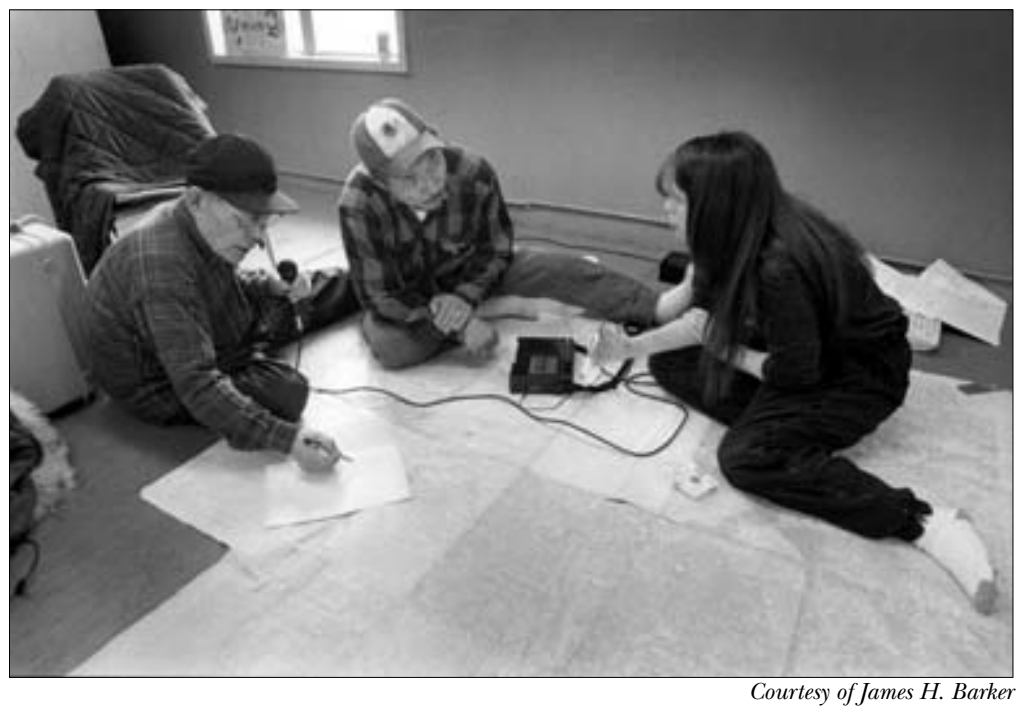

Mapping place names and place narratives, 2001.

girls sinking down into the earth she suddenly turned to her own story and a similar experience that she had with this sentient land. Her story, also, seemed to highlight the important relationship of respect for a sentient land.

She began her story by telling us of a young boy in Hooper Bay whom she had cured with water found at a special location on the tundra. This small boy had suffered an illness that resulted in a serious affliction of his arms, neck, trunk, and face. She described how she went to this place on the tundra to collect the water to heal this child. She explained to us that she wanted to thank the land (nuna) for the healing waters and that she felt she had so little to offer. She tells us, her listeners, that she had thought about it for a long time and finally decided that she would offer, as a gift, her sewing needle. This was, indeed, a significant gift, as she is well-known and admired for her sewing and basket making even to this day.

She reenacts the careful placement of the bone needle as though she is doing it at the very moment of her telling. She explains to us that sometimes the land will reject a gift, not accept it from the people who offer it. She laughs uncomfortably as she recalls how very nervous she felt as she gently placed the bone needle down into the tundra waters. Her hand still extended out, she stares ahead as though she is there now, nervously watching it as it floats on the surface of the water. As she tells this story, her eyes remain fixed 
on a single object. She does not see us (her listeners) or the empty conference room where we are sitting. She is watching that needle float. She is waiting to see if this gift will be accepted. Her face lights up suddenly as she describes her great relief and joy at the sight of the needle slowly disappearing under the water. She knows that her gift of thanks has been accepted. "Oh, I was so happy!" she says as she fondly remembers this powerful life experience. This narrative, like the story of "The Giant Footprints," gives us a sense of a complex and overlapping world. It also beautifully illustrates the ongoing relationship of reciprocity and respect that Yupiit maintain with the land and also how stories are embedded in life experience. In this case, the giant footprints serve as a springboard for this teller's personal story of her own interaction with the land and the acceptance of her gift.

One of the most recent tellings of "The Giant Footprints" was shared with me in the fall of 2002 during a recorded interview. Interestingly, this telling would also be linked to another narrative that was very similar in content and form. This particular community elder stated that his grandfather and father often told him the story and that he would see the footprints at that place out on the land when he was hunting.

Elder: "I used to go bow and arrow, bird hunting" [at that place].

Holly: "Yeah, you would see them?"

Elder: "Tamana" [refers to that place spoken of. Out, over there, extended space].

Listener: "Ii-I" [yes, another listener who nods his head in agreement].

Elder: "Uh, growing up, [I would often see] those footsteps from these young girls, that just got into their [first time]. Two young girls that just started having their periods."

Elder: "They [the footprints] used to be deep when I was young, back then."

Elder: "When they went down to the dance, they say they went under the usual path; I think they went under the ground.

At this particular point in his telling he makes an abrupt leap from the tale of the giant footprints to another story. The story of the giant footprints becomes linked to a longer, embedded 
narrative in which a group of children also become lost in the land at a place he calls the Volcano Mountains. The teller states that these children "go under the ground." This occurs when they fail to listen to the important teachings of their elders, carelessly passing through the underground passageways during a ceremonial time. ${ }^{6}$ This was a time when the human and spirit worlds were closer, a time when the boundaries between worlds were diminished.

It is said that when they went into one of the houses, they missed the path that went into the house, but instead went under the path, in those qasgi. . . . They say they went out through the ground. . . Yeah, they went below the underground entrance, when they tried to go in through the underground entrance, they began to travel through the ground underneath the tunnel.

Like the narrative of the giant footprints, this tale is about more than just getting lost on the land. The children become, for a time, a part of the land at this place known as the Volcano Mountains. This teller described the parents' anguish as they could hear their children crying for help but were unable to reach them. Morrow notes that this is a well-known Yup'ik story often told in connection with Qaariitaaq. She writes, "In this way, they [the lost children] acted like the spirits of the dead, who gathered under the qasgi for ceremonies when the people invited them to come from the underworld" (Morrow 1984:122). Unlike the girls who left the giant footprints, these children eventually resurface at the Volcano Mountain, returning to the world of the living. The teller explains that when they come out "they're really old, really old!" These two narratives are linked not only because they are similar in content. They are linked by their connection to particular places on the land, places that are aware and responsive. It seems to me that certain places hold a greater potential for human contact with the spirit world.

This became clear to me one day while out collecting driftwood with my friends. They offered to take me to the abandoned village site near the giant footprints. From both the air and ground, one can see the remains of large, dome-shaped semisubterranean sod houses where the Hooper Bay ancestors once lived. I was eager to explore this abandoned village site and quickly climbed one of the earthen mounds. I was even able to crawl through an opening that once served as a tunnel, doorway entrance. Slightly collapsed, the wooden support beam was still in place and, although it was a tight squeeze, I managed to crawl through the passageway of this 
dwelling. Nelson described these passageways at Askinuk in great detail, stating that:

The houses are clustered together in the most irregular manner, and the entrances to the passageways leading to the interiors open out in the most unexpected places. Sometimes one of these passages opens on the top of another house built lower down on the side of the mound, or, it may be, between two houses, or almost against the side of an adjoining one. (Nelson 1983 [1899]:249)

Passing through this entryway was a momentary event, but one I would always remember. As I crawled through this passageway I had a strong sense of touching history, but I immediately noticed that this made my Yup'ik companions very uneasy. At the time I did not understand why this would make people so uncomfortable. I was truly puzzled by their look of concern. I even examined the structure, wondering if it was unsafe. I just could not understand why they seemed so uneasy with my actions. I also wondered why the Hooper Bay ancestors had left this place. ${ }^{7}$ At the time, I lacked the cultural contextualization that narratives of place provide and thus the knowledge of how to act appropriately. After several years and many more stories, I would come to understand their sentiment better. I would also, through narratives of place, come to see my own actions as foolish and careless.

I have heard the story of "The Giant Footprints" told many times over the years. Each telling explains how these footprints came to be. The place of the giant footprints exists as a tangible and concrete reminder of deeply rooted Yup'ik knowledge and shared contemporary values. Each telling and each allusion to this place reinforces the importance of respecting the wisdom of community elders. These tellings underscore the importance of Yup'ik knowledge by highlighting the potentially serious effects of dismissing it. Clearly, the story of "The Giant Footprints" is an important one that continues to hold meaning for the people of Hooper Bay. This narrative, as well as the story of "The Children Who Came Out at the Volcano Mountains" and the narrative in which the elder gives "A Gift to the Land" all demonstrate that the landscape is much more than an inanimate place. Human beings are not separate and distinct from the natural world but are instead very much a part of it. This sense of place includes the world of spirits and other beings who inhabit the tundra, the waters, and other features of the world around them. 
This is a lived "sense of place" where wisdom sits in places (Basso 1996). These places remind Yupiit of their cultural values and beliefs, but they also react to human behavior. The land, in essence, is a social actor capable of directly responding to human actions. Like the seals who are hunted and those of the spirit world, places on the land are always watching and aware. Like people and other creatures, the land responds both positively and negatively, depending on the context of the particular event or human action. The needle was accepted and brought joy to the land. The elder who linked the Volcano Mountains story to the giant footprints also informs his audience that "they [the footprints] used to be deep when I was young back then." I strongly suspect that this description of the changing depth of the footprints parallels the many descriptions of an often "thicker" land in contemporary times. This "thickness," I am told, has decreased the permeability between the contemporary human and spirit worlds. A thicker land ${ }^{8}$ and diminishing footprints are both signs of a world that is not well. ${ }^{9}$ There is a sense that when the community is not well, the land and spirit world are not well. Perhaps the earth's thickness and diminished land features are in direct response to diminished awareness and sensitivity to the spirit world?

The giant footprints, the actual depressions, are cognizant of human actions and continue to inform people. They hold symbolic import, serving as a tangible reminder of the importance of Yup'ik teachings and belief for community members but simultaneously serving as a strong cautionary tale for outsiders who lack the knowledge to behave properly. ${ }^{10}$ Thus, those giant footprints reinforce the fact that the world can also be a dangerous place for those nonYupiit who do not respect Yup'ik ways.

It has been more than ten years since that seal eluded us. Then I questioned the young hunters' skills, but now I have come to believe that my very presence, as a female, is a more plausible explanation for its loss. Women today, as in the past, don't typically go out seal hunting with men. I now believe that I was led to those giant footprints for a particular reason. Within a Yup'ik context, the telling was both an explanation for the loss of the seal and a cautionary tale for this then-newcomer. It took almost a decade for me to understand why this story may have been shared with me that long ago July evening. As in much of Yup'ik instruction, I was not told what to learn from my experience or the story. I was left to find meaning as my life unfolds. 
The way that places are consulted for guidance is characteristic of the Yupiit of Southwestern Alaska. The land is a being among beings, and a particularly powerful and sensitive one. For Yupiit in Hooper Bay, places and stories are not simply symbolic, they are active elements of social life. As Elsie Mather, a respected Yup'ik educator, reminds us, "storytelling is part of the action of living" (Morrow and Schneider 1995:33).

\section{Notes}

1. Yupiit believe that game animals "present" and give themselves to those who demonstrate respect and proper behavior (Hensel 1996).

2. Hensel (1996) notes that seal oil remains a highly valued food item throughout the Yup'ik region.

3. This motif (girls who have just had their first period and are tempted by curiosity) is a common prelude to trouble in Yup'ik Eskimo stories (Morrow 2002).

4. Alternately referred to as "giant footsteps."

5. Morrow notes that numerous rules guided women's behavior at menarche (Morrow 2002).

6. This ceremony was identified as qaariitaaq (also the contemporary word for Halloween), but as linguist Steve Jacobson notes qaariitaaq was a Yup'ik ceremony that predated contact (Jacobson 1984:302). Phyllis Morrow (1984) and Elsie Mather (1985) identify qaariitaaq ("going in and out of houses") as the first of many ceremonies that preceded the Bladder Festival.

7. Epidemics forced the abandonment of villages throughout Alaska. Hooper Bay community member Harold Napoleon writes that his ancestors were "too weak to bury all the dead" and that "many survivors abandoned the old villages, some caving in their houses with the dead still in them. Their homeland-the tundra, the Bering Sea coast, the riverbanks—had become a dying field for the Yup'ik people" (Napoleon 1991:11).

8. The thickness of the earth today is not static. There is still the potential for a change in the thickness of the land in response to human actions, but perhaps less often than in times past. In a personal communication with Phyllis Morrow (2006) she stated that she has also heard that the earth becomes "thinner or thicker in response to that relationship."

9. I have often encountered talk of diminished land features in the form of metaphoric speech. For example, one teller, who wished to avoid direct talk of painful events, abruptly stated that the tundra ponds don't have as much water as they once did and that there are no more flowers on the land.

10. What Keith Basso (1979) refers to as "blundering fools" in Western Apache storytelling. 


\section{References}

AM Collection, Alaska Mission Collection. John P. Fox, S. J., Collection, Microfilm Roll 30. Oregon Province Archives of the Society of Jesus. Gonzaga University, Spokane, Washington.

Basso, Keith H. 1979. "Portraits of the Whiteman": Linguistic Play and Cultural Symbols Among the Western Apache. Cambridge: Cambridge University Press.

— 1996 Wisdom Sits in Places: Landscape and Language Among the Western Apache. Albuquerque: University of New Mexico Press.

Hastrup, Kirsten. 1997. A Place Apart: An Anthropological Study of the Icelandic World. Oxford: Clarendon Press.

Hensel, Chase. 1996. Telling Our Selves: Ethnicity and Discourse in Southwestern Alaska. New York: Oxford University Press.

Jacobson, Steven A. 1984. Yup’ik Eskimo Dictionary. Fairbanks: Alaska Native Language Center.

Mather, Elsie. 1985. Cauyarnariuq [A Time for Drumming]. Bethel, Alaska: Lower Kuskokwim School District.

Michael, Henry N. 1967. Lieutenant Zagoskin's Travels in Russian America 1842-1844: The First Ethnographic and Geographic Investigations in the Yukon and Kuskokwim Valleys of Alaska. Toronto: University of Toronto Press.

Morrow, Phyllis. 1984. It is Time for Drumming: A Summary of Recent Research on Yup'ik Eskimo Ceremonialism. In The Central Yupik Eskimos, supplementary issue Etudes/Inuit/Studies, vol. 8 edited by E. S. Burch, Jr., University of Laval, Quebec, Canada. 2002A Woman's Vapor: Yup'ik Bodily Powers in Southwest Alaska. Ethnology 41 (4):335-48.

Morrow, Phyllis, and William Schneider, eds. 1995. When Our Words Return: Writing, Hearing, and Remembering Oral Traditions of Alaska and the Yukon. Logan: Utah State University Press.

Napoleon, Harold. 1991. Yuuyaraq: The Way of the Human Being. Fairbanks: Center for Cross-Cultural Studies, College of Rural Alaska, University of Alaska Fairbanks.

Nelson, Edward W. 1983 [1899]. The Eskimo About Bering Strait. Washington: Smithsonian Institution Press.

Oswalt, Helen. 1951. Ethnological Notes from Hooper Bay. Unpublished MS, Alaska and Polar Regions Department, University of Alaska Fairbanks.

U.S. Bureau of the Census. Report on the Population and Resources of Alaska at the $11^{\text {th }}$ Census, 1890. United States Census Office. Washington, D.C., 1893. 


\title{
The Giant Footprints
}

\author{
A Conversation with Holly Cusack-McVeigh and \\ Klara B. Kelley
}

\begin{abstract}
Holly Cusack-McVeigh and Klara Kelley explore the role of place in Yup'ik and Navajo oral tradition. They discover that the contexts for sharing narrative in both traditions are very different; Cusack-McVeigh finds that her Yup'ik friends see sites like the Giant Footprints as barometers of social well-being and they share with each other how their experiences relate to the traditional story and the site. Kelley, drawing on work with her Navajo colleague, Harris Francis, indicates that the Navajo sacred sites are described in a rich oral tradition that is only told in winter and in the context of ceremonies. Individual Navajo may relate this knowledge to their experiences, but the tellings of the ancient stories and of stories about personal experience with the sites are separate. Young people in Yup'ik and Navajo culture therefore have different types of opportunities to learn, relate to, and participate in their oral traditions. Both Cusack-McVeigh and Kelley acknowledge that there may be fewer such opportunities in these cultures where youth are reminded of the importance of the stories and where they would hear the ancient accounts referenced. Yup'ik elders express concerns over the impacts of a rapidly changing world and, in the Navajo case, children are often not on the reservations in winter when the ceremonies are held and the stories told.
\end{abstract}

SCHNEIDER: I want to begin with something Holly said in her last e-mail to me. She said that "place anchors memory" and so I thought we should start with that and then see how new events get associated with places in our memory. So Klara, when Holly says,

Klara B. Kelley is an anthropologist who has been working for many years with Navajo people in the American Southwest. She has teamed with Harris Francis, a Navajo cultural expert, to document the cultural meaning of Navajo historic sites. They are the authors of Navajo Sacred Places (1994). 
"place anchors memory," how does that relate to your experiences working with Navajo people?

Kelley: Well, I think places are an anchor for personal and social memory. Of course, people have their own personal experiences, but because there are particular oral traditions that they have been taught to remember in detail, and because these have been handed down through many generations in a particular way, these form what we might think of as a landscape constructed by many generations. Navajo people relate their personal experiences to that ceremonial landscape, and that kind of reinforces the ties between personal experience and the oral traditions of their society, the past and the present. But personal experiences don't get mixed into or retold as part of the oral tradition that is recounted in the ceremonies.

What has always been emphasized for those of us who do research here in Navajo country with oral tradition is how well-preserved the ceremonial narratives are. The narratives are part of ceremonial repertoires - there are a couple of dozen repertoires-and these repertoires also include songs, prayers, paraphernalia, ritual procedures, sand paintings, and body painting. And the repertoires also include rules for combining these elements into a particular ceremonial performance for a particular purpose at a particular time and place. Parts of ceremonial narratives may be told during ceremonies, and each telling is tailored to the reason for the ceremony. But even so, the tellings are closely similar in each retelling. These ceremonial repertoires are big and elaborate and involve a lot of memorization of procedures and instruction on how to do the rituals, sand paintings, dance performances, and so forth. It takes years to learn these things. Well, each of these repertoires has a collection of narratives about its origin and development, and it is always emphasized that these have been handed down and you have to learn them just as told-not verbatim, the way songs and prayers are learned, but with the exact group of actors, events, and so forth. Those who learn more than one version are very careful that they tell one version or another but they don't combine those things and they don't put their own experience in the narrative. They may break out of narrative to comment or something like that, but that kind of personal experience or personal knowledge doesn't get into those narratives as they are handed down and there is a real concern about preserving the integrity of these narratives. 
Many of the Navajo stories are only supposed to be told in the context of ceremonies in the winter time. When people like me do research, we haven't been taken out as a child and instructed. I'm more of an institutional link. I do my work kind of like you, Holly, do your work; we come into these communities as professionals rather than as integrated community members who will live in the community and carry on the traditions. But, with that as a caveat, let me give an example that may help to demonstrate the relationship between personal experience, ceremonial knowledge, and places out on the land.

I almost always work with one particular Navajo colleague. His name is Harris Francis. I guess it was about this time of year. We had talked to a ceremonialist for quite a while. This was a ceremonialist that Harris was fairly close to, and he had already told us a particular story. It is one of the ones I guess like the "Giant Footprints," one that kids tend to be told, not one of the more esoteric (and secret) ones. This was one that everyone knows, one you hear over and over again in different versions. This telling by the ceremonialist is the only one we have encountered that traced a route of travel on the ground for the heroes of the story. The ceremonialist had named a series of places and identified them for us in relationship to current landmarks and towns, and stuff like that. (That's the background.) Then, one time Harris and I were with this ceremonialist in view of one of those places, and the ceremonialist related how once in the past, he had driven down there and encountered these giant ants. In this case I can't say there was a clear moral lesson there, but I think in a way the point the ceremonialist was making to us is that this is not something we normally encounter and that this was a sacred zone. The unexpected happens in those kinds of places. That was his personal experience in this place that was named in this very ancient and well-known story. Most people can't even approximate where the place of that name is on the ground, but he could (because of what he had been told) and he was bearing witness to us that he had experienced something counterintuitive that validated what he had been taught about that area being a sacred zone. So when there is personal information like when you go to a place and someone alludes to an episode in one of these ceremonial stories, they will treat it the way the ceremonialist treated his experience with the ants, but those ants would never get into the age-old narrative of the heroes. The personal stuff is kept separate from the more traditional telling, but it's not 
unrelated; you just have to be careful how you structure your discourse to make those distinctions clear. You have to step out of the story if you want to apply a personal lesson. That's the way it is here, at least in my experience.

CusAck-McVeigh: Interesting, because I can think of several situations where a teller will shift (in the same breath) from a well-known narrative to a more personal narrative describing an encounter, like the one you described with the giant ants, that is known to be out of the ordinary. And, as you said, it is a place marked by unexpected events. I have often wondered if that becomes more emphasized for the outside audience as another way to establish the value of the oral tradition, the old story that is the referent.

In one instance, an elder described an encounter with several otters and how they just weren't right; there were too many in one place. He knew right away he was at a place that was more significant than other places where one might encounter otters.

Another example where story, place, and social conditions come together is the shaman's grave at Hooper Bay. One teller alluded to this grave, explaining that in Yup'ik tradition, people were buried above ground. You can look out onto the tundra and still see these old graves today. On my first visit to Hooper Bay, I was told about the shaman's grave by a woman who had learned about it from her mother. Only once did she explicitly state to me that the shaman's grave was sinking (becoming level with the tundra) and that this was a sign of worsening conditions in her community and the larger world. She alluded to this place, I think, by way of getting me to recognize and take notice of the grave as a sign of conditions. Each time I returned to her village she would greet me by saying that "the shaman's grave is getting lower." This teller knows that I have enough cultural context to understand that this means, in her mind, things are much worse. This is also an example of how in Yup'ik discourse, some things are just too dangerous to mention directly. To speak explicitly of a painful event would be to invite it into one's own life. So the place of the shaman's grave provides this speaker a way to talk about things that cannot be otherwise spoken. And this works because I know the story and the place.

SchneIDER: In the Yup'ik examples you gave us, one's personal experiences in a way confirm the old stories, and the places reinforce the message. 
Cusack-McVeigh: Yes. The places and the stories are reminders of how to behave and the potential consequences of not following the rules of the society. The story of the "Giant Footprints" is, however, one of the strongest examples I have encountered in different contexts.

SchneIDER: Yes, that is one of the strengths of your paper: the attention to how the story is used. It seems clear that the "Giant Footprints" is really a cautionary tale and as such it is meant to be applied and told in the context of giving an indirect lesson, as opposed to telling someone directly that they are not acting right.

Cusack-McVeigh: Well that is one of the things that it does. It is a cautionary tale particularly and primarily for those who are of the culture and are thought to be getting further and further from their cultural traditions. In many Native communities, that is a primary concern, because kids drift from their cultural values and social situations worsen. It also serves as a cautionary tale for those outside the culture who don't know the dangers and cultural ways.

Kelley: Yeah, I think that is a concern around here too. There are some Navajo people who have been raised as Christians or are younger and are thought to not know anything about their culture. People are skeptical of them because all they have experienced is public school. Sometimes they are lumped into the same category as outsiders, and the attitude toward them is linked to the admonishment: "don't put aside your traditions. This is who you are, and you'll be nobody if you don't keep learning these things."

Cusack-McVeigh: Yeah, these stories point out the real potential danger of letting the cultural traditions go. Places don't just remind people of story, places respond to human thought and action. Through stories of place, listeners can learn from the mistakes and naiveté of others. The place of the giant footprints remains significant in contemporary times because it speaks to people about the importance of following the words of their elders.

SCHNEIDER: It is appropriate that our discussion has brought us to the role of stories in establishing and maintaining the social order and the support systems of a culture. We have seen the power of story to operate in the personal sphere, as in your experiences, Holly, and through what you, Klara, have called the "received oral tradition." The linking of story to place in both ways anchors experience and memory to the landscape and is a strong form of reinforcement. 